\title{
STUDIES ON THE DEVELOPMENT OF THE CRAB PUGETTIA QUADRIDENS (DE HAAN) : 1.HATCHING AND ZOEAE
}

$\operatorname{AUTHOR}(S)$ :

Iwata, Fumio

CITATION:

Iwata, Fumio. STUDIES ON THE DEVELOPMENT OF THE CRAB PUGETTIA QUADRIDENS (DE HAAN) : 1.HATCHING AND ZOEAE. PUBLICATIONS OF THE SETO MARINE BIOLOGICAL LABORATORY 1970, 18(3): 189-197

\section{ISSUE DATE:}

1970-11-25

URL:

http://hdl.handle.net/2433/175631

RIGHT: 


\title{
STUDIES ON THE DEVELOPMENT OF THE CRAB PUGETTIA QUADRIDENS (DE HAAN): 1. HATCHING AND ZOEAE ${ }^{13}$
}

\author{
Fumio IWATA \\ Zoological Institute, Faculty of Science, Hokkaido University, Sapporo, Japan
}

With 1 Text-figure and Plates I-II

Among the Brachyuran larvae recorded from Japan (Aikawa '29, '33, '35, '37, '41; Takeda and Mryake '68), the first zoea of Pugettia quadridens (Brachyura, Majidae) has been described by Aikawa ('29, p. 38 and 39), who obtained the larvae from the berried crabs. In the winter of 1969 , the present writer had a chance to observe the development of $P$. quadridens collected on the Pacific coast of the southwestern Hokkaido, North Japan, and came to a conclusion that his first zoea obtained shows many differences in structure in comparison with that of Aikawa. As the crabs studied by Aikawa were collected on the Pacific coast of the southern Kanto District, Middle Japan, the differences between the characters of the both larvae may be either due to the environmental or to the genetical differences. The present paper deals with the development of Pugettia quadridens from northern Japan, especially regarding the hatching of eggs and characters of the pre- and first zoea.

The crabs for the present observation are stocked in the Zoological Institute, Faculty of Science, Hokkaido University, Sapporo, Japan.

Before going further, the writer wishes to express his cordial thanks to Prof. emer. Dr. Tune SAKaI, Faculty of Education, Yokohama National University, Yokohama, for his kind suggestions on the identification of the present species. Thanks are also due to Prof. emer. Dr. Tohru Uchida for his kindness to read through the manuscript.

\section{Material and Methods}

The crabs used for observation were collected at Usu on the coast of Funka Bay on the Pacific side of the south-western Hokkaido, North Japan, and reared in a small glass tank in the laboratory of our University in Sapporo. The glass tank filled with sea water was put in running water which was kept in constant temperature $\left(10^{\circ} \mathrm{C}\right)$. The

1) Contribution No. 887 from the Zoological Institute, Faculty of Science, Hokkaido University, Sapporo, Japan.

Publ. Seto Mar. Biol. Lab., XVIII (3), 189-197, 1970. (Article 13) 
sea water in which the crabs were reared, was aerated constantly by an air compressor. The meat of the mussel Mytilus edulis was given as food.

A couple of crabs were put together in the glass tank on November 22, 1968, and the copulation between them was observed on December 8 . Later four females and one male collected on December 21, 1968 were added in the same container. The spawning was first observed on January 21, 1969. Since then the eggs were obtained every day until February 10. The last eggs used for observation were spawned on March 19, 20 and 22. The eggs released in the glass tank were removed into the glass bowls. The microphotography was used for observations of the differentiation of eggs and on the characters of zoeae. The eggs and larvae were fixed in Bouin's fluid.

The present crabs were identified by Dr. Tune SAkai as Pugettia quadridens (DE HAAN), the male and female of which are seen in natural color in his book "The crabs of Sagami Bay" (SAKai '65).

\section{Result}

Outline of development: ${ }^{1)}$ The egg just spawned is covered with a sticky jelly membrane with a long funicular stalk. The fertilization of eggs occurs internally as usual. The egg is red or orange in color and measures about $0.5 \mathrm{~mm}$ in diameter. The second polar body is found inside the jelly membrane at the base of the funicular stalk. After the gastrular stage, the ventral plate and optic lobes are differentiated, forming between them a V-shaped furrow which later shortens antero-posteriorly, forming an elliptical blastodisc. The rudiments of the antennule, antenna and mandible are elevated on either side of the blastodisc. The mouth of the foregut is observable from above the egg at the middle of the blastodisc between the rudiments of the antennule and antenna. A small limited part of the blastodisc between the mouth of the foregut and the anterior end of the ventral plate moves inward and comes to lie under the ventral plate. The mouth of the foregut then contacts immediately with the anterior end of the ventral plate. The rudiments of the maxillule and maxilla, which are recognizable in the nauplian stage, are arranged behind the mandible.

The thoracico-abdominal somites of the body, such as the maxillipeds, legs, abdomen and telson of the crab, are originated from the ventral plate. After the nauplian stage, a small part of the blastodisc immediately under the ventral plate is elevated upward and fuses with the ventral plate. After this stage, the ventral plate becomes voluminous and elongates toward the back of the blastodisc. It is separated into two parts from above the egg, of which the anterior one is short and slender, being bifurcated, while the posterior one is longer and wider, being elliptical

1) Spoken already at the 40th meeting of the Zoological Society of Japan held at the Tempu Hall, Otsuka, Bunkyo-ku, Tokyo on October 3, 1969. 
in shape. On each side of the posterior part of the ventral plate, there come to appear two buds protruded laterally, of which the anterior one becomes the second maxilliped, while the posterior one, the first maxilliped. The bud of the third maxilliped appears later in development at the level anterior to that of the second maxilliped. These buds move toward the back of the blastodisc as the bifurcated part of the ventral plate elongates posteriorly. They bend outward and come to the place parallel to the ventral plate. The bud of the first maxilliped thus comes to the place behind the rudiment of the maxilla. The rudiments of the legs and abdomen appear in the ventral portion of the ventral plate between the rudiments of the maxillipeds: the former, in a pair, is discoidal in shape and moves anteriorly along the ventral side of the ventral plate, reaching the portion above the rudiments of the maxillule and maxilla; the latter becomes thicker and voluminous, extending anteriorly as the bifurcated part of the ventral plate, but becomes again shorter later. The rudiment of the abdomen is then differentiated into six somites, while those of the legs into five segments. The bifurcated part of the ventral plate, which is composed of two segments, becomes the caudal furcae and telson of the zoea. In later stages of development, the status of the formation of the compound eyes, differentiation of the chromatophores and elongation of the lateral nerves are observable through the egg shell. The prezoea escaped from the egg shell develops into the first zoea without ecdysis.

Hatch of eggs: In the egg just before hatching, there can be easily observed through the egg shell, the large compound eyes, three chromatophores lying at the bases of the first and second maxillipeds and on the carapace, and a reddish patch of the deutoplasm situated near the egg center beneath the compound eyes (Pl. I, a, $d, e, c h)$. The eggs become voluminous during their differentiation, their diameter reaching about $0.65 \mathrm{~mm}$. It took about 35 days to complete the differentiation in the $11^{\circ} \mathrm{C}$ sea water. At the beginning of the hatching, the egg shell is sharply cut by strong movements of some body parts such as the maxillipeds. The cut is made transversely to the antero-posterior axis of the prezoea (Pl. I, f). The maxillipeds come to appear at first outside the egg shell and then the abdomen follows (Pl. I, b, d; Pl. II, a). The prezoea hatched out is translucent and whitish in color.

Prezoea: In the prezoea just escaped from the egg shell, the dorsal, rostral and lateral spines are not yet observable except a short needle-like seta lying close to the dorsal surface of the carapace (PI. II, a, ns). The seta is issued from the rudiment of the dorsal spine which is seen blackish in figure $(r d)$. One chromatophore in a concentrated state is found immediately under the seta. In a few days after hatching, the dorsal spine comes to appear at the mid-dorsal portion of the carapace, the needle-like seta standing on its tip (Pl. II, b and c). The antennule, a rather long process in the first zoea, is still elliptical in shape, while the antenna, longer than the former, is sickle-shaped in the lateral view (Pl. I, c, an; Pl. II, a, an, ae). In this stage 
the endites of the antenna are already complete in form. The exopod is provided with three setae, of which two are paired and shorter than the other central one; the peduncle is considerably shorter than the exopod; the endopod is elliptical in shape. The labrum is large and rounded in shape, being swollen on the ventral end (P1. II, a, l). One chromatophore is found on the antero-ventral side of the labrum. The mandible is rectangular in shape in the lateral view and is toothed on its ventral end (Pl. I, c, m). The maxillule and maxilla are slender than the mandible; their endites are distinguishable (Pl. I, c, ma, me). The chromatophore seen at the base of maxillule $(m a)$ is really situated on the ventral wall inside the maxillule. In the first maxilliped the five-segmented endopod is longer than the two-segmented exopod, while in the second maxilliped the endopod is much shorter than the exopod and both endites are two-segmented (Pl. I, c, fm, sm). Among six abdominal somites, the first to fifth are same in length and shape, while the sixth one is half the length of respective preceding segments ( $\mathrm{Pl}$. II, a, $V s, s s)$. The chromatophores on the abdomen are arranged as follows: one covering the first and second somites; three on the third, fourth and sixth respectively. Those on the third and fourth somites are situated at respective postero-ventral ends; though that of the sixth at the antero-ventral end (Pl. I, e, ch, ss, Vs; Pl. II, a, ss, Vs). The chromatophore is wanting on the fifth somite. The buds of the pleopods are clearly observable on the second to fifth abdominal somites (PI. II, a, bp). The telson has lateral spines, and the caudal furca has two spines extending posteriorly ( $\mathrm{Pl}$. I, e, $c f, t e)$. It must be noted that the boundary between the telson and the caudal furca is clearly observable as seen in $\mathrm{Pl}$. I, e, bo. Later in the first zoea, the sixth abdominal somite, telson and caudal furca fuse into one part of the abdomen, namely the so-called telson (Fig. 1, j, $f f, s s, t e$ ). The third maxilliped and buds of the legs are furnished on the ventral wall between the second maxilliped and the first abdominal somite (Pl. II, a and $\mathbf{b}, b, t)$. Under the microscope, there was found a thin chitinous membrane covering the dorsal side of the carapace, when the prezoea hatched out. The antenna and telson are covered with long chitionus sheathes, which are cast off later.

First zoea: Between the instars of prezoea and first zoea, there occur some changes in body characters without any ecdysis, such as the appearance of the dorsal and rostal spines, the formation of the so-called telson, and the elongation of the antenna. The first zoea measures as follows: rostral spine $0.24 \mathrm{~mm}$ long; dorsal spine $0.6 \mathrm{~mm}$ long (from tip to posterior angle between the spine and the carapace); antenna $0.53 \mathrm{~mm}$ long; distance between ends of the two spines $1.5 \mathrm{~mm}$; antero-posterior length of the carapace $0.8 \mathrm{~mm}$; interorbital distance $0.43 \mathrm{~mm}$; the first to fifth abdominal somites $0.93 \mathrm{~mm}$ long; distance between the anterior end of the sixth abdominal somite and the posterior end of the caudal furca $0.69 \mathrm{~mm}$ long. The dorsal spine is considerably longer than the antenna and is much longer than the rostral spine (Pl. II, $\mathrm{d}$ and $\mathrm{e}, a n, d s, r)$. The lateral spine is wanting. The antennule has aesthetes, one smaller seta and one short hair (Fig. 1, b). The antenna, which is much 
longer than the rostrum, has the following characters: the peduncle is furnished with two rows of short spines on the distal surface and is slightly longer than the exopod; the endopod is elliptical as in the prezoea (Fig. 1, c). The mandible is toothed on its ventral end as seen in Fig. 1, d. The maxillule has the following characters: the endopod consists of two segments, of which the distal one bears four terminal setae, while the proximal, one seta; the basipod has six spines, of which one is situated at its basal portion facing to the coxopod, while among others arranged on the ventral side, two are stout and two are arranged in a pair between the former stout ones; the coxopod has seven spines (Fig. 1, e). The endites of the maxilla are bilobed into anterior and posterior portions at their ventral edge (Fig. 1, f). Number of setae on the maxilla is as follows: endopod with 2-3 setae; basipod with 4-5; coxopod with 2-4; and scaphognathite with 5 ones. The first and second maxillipeds have each four swimming setae on the exopod (Fig. 1, g and h). The five-segmented endopod of the first maxilliped has the setation 5-3-1-2-3 from distal to proximal, while the two-segmented endopod of the second maxilliped with the setation 4-1. The exopod of the second maxilliped is indistinctly segmented (Fig. 1, h). The protopodite of the first maxilliped is furnished with setae arranged as 3-2-2-2 from distal to proximal, while that of the second maxilliped with 3 spines (Fig. 1, g and h, pr). In the so-called telson, the sixth abdominal somite is still recognizable from above the body by a slight boundary line at its posterior end (Fig. 1, j, ps). The telson has a lateral spine on each side and three pairs of spines on its inner surface. The abdominal somites from the third to the fifth terminate each in a small spine at each posterolateral corner (Fig. 1,j). The ventral marginal edge of the carapace is sparsely haired, only four on each side. The buds of the pleopods of the abdominal somites become rod-like in shape (Pl. II, e). The third maxilliped is shown in Fig. 1, i. The chromatophores, noted as reddish dots in preserved specimens, are arranged as follows: one on the anterior wall of the labrum; one on the ventral wall of the head beside the labrum; one on the mandible; one inside the maxillule; two at the bases of the first and second maxillipeds; three on the marginal portion of the carapace, of which two are smaller than the other; one on the median gastric wall; one on the boundary between the first and second abdominal somites; one on the central portion of the carapace; one on the anterior basal portion of the dorsal spine; three on the third, fourth and sixth abdominal somites respectively.

\section{Discussion}

For the identification of brachyuran zoeae, Arkawa ('29) cited the following four characters (1) spines on the carapace, (2) character of the second antenna, (3) character of the telson, including its armature, and (4) grouping of chromatophores. And the characters given by him for the first zoea of $P$. quadridens are as follows: second antenna A-type; telson A-type, with two outer teeth; primary chromatophores in both 

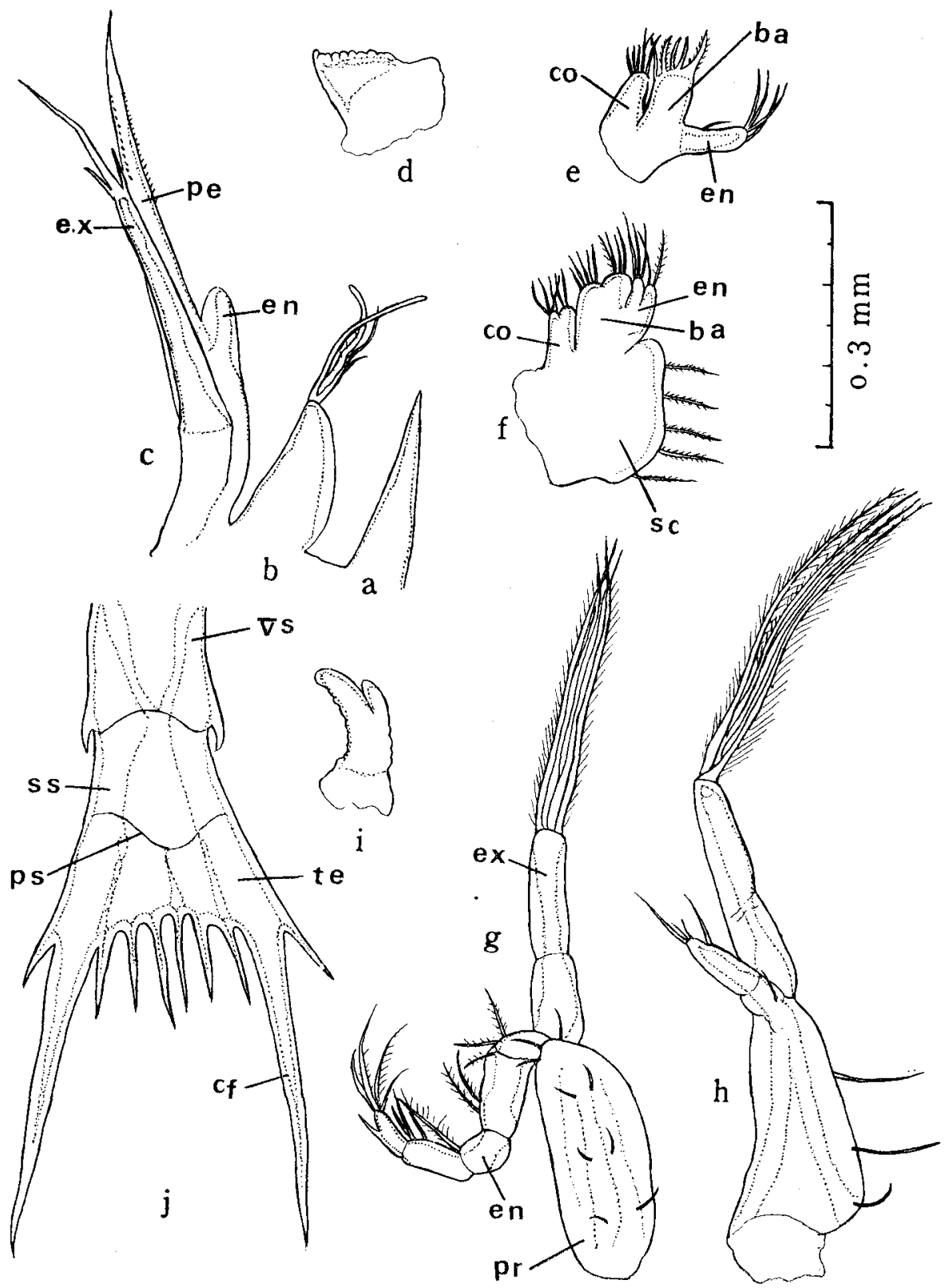

Fig. 1. The first zoea of Pugettia quadridens (DE HAAN). a. Rostral spine, b. Antennule, c. Antenna, d. Mandible, e. Maxillule, f. Maxilla, g. First maxilliped, h. Second maxilliped, i. Third maxilliped, j. Telson. ba. basipodite, cf. caudal furca, co. coxopodite, en. endopodite, ex. exopodite, pe. peduncle, pr. protopodite, ps. posterior end of the sixth abdominal somite, sc. scaphognathite, ss. sixth abdominal somite, te. telson of the prezoea, Vs. fifth abdominal somite. 
maxillipeds; abdominal chromatophores present in first and second somites in common, in third to fifth somites and in telson. In comparison with the characters given above, the first zoea of the present material mainly agrees with the AIKAwA's except a few minor points as follows: telson provided with one outer tooth; chromatophore wanting on the fifth abdominal somite.

As to other characters, however, the AIKAWA's first zoea differs somewhat from the first zoea of the present material in fifteen points as follows: (1) antennule with two aesthetes and three hairs; (2) peduncle and exopod of the antenna similarly toothed on either side in the distal half; (3) labrum coarsely haired at sublateral corners; (4) mandible bilobed, irregular in shape; (5) maxillule with 5 setae on coxopod, 6 on basipod, and 1-4 on endopod; (6) maxilla bilobed in its endites except the endopod, with 3-3 setae on coxopod, 4-5 on basipod, 4 on endopod, and 10 scaphognathite; (7) first maxilliped with 2-2-1-2 setae on protopod and with 5-2-1-3-3 setae on endopod; (8) second maxilliped with 1-1 setae on protopod and with 3-1 setae on endopod; (9) abdomen shorter, measuring $0.8 \mathrm{~mm}$ through five somites and $0.36 \mathrm{~mm}$ in telson; (10) rudiments of the pleopods wanting; (11) second abdominal somite having a small spine at its postero-lateral corner; (12) distal part of telson-fork finely serrated all over; (13) lower margin of carapace coaresly haired; (14) no chromatophores inside the maxillule, outside the labrum and on the anterior basal portion of the dorsal spine; (15) chromatophores present on supra-cerebral, antenna, post cardiac, optic center, and on median ocular center.

Moreover, Aikawa did not give any description on the sixth abdominal somite, third maxilliped and buds of the legs, and prezoea, though the third maxilliped and buds of the legs are seen in his figures ('29, Pl. 3, 19). It is unkown whether or not the AIKAwA's first zoea was the form escaped immediately from the egg shell.

It is interesting to note that the crabs from Hokkaido released eggs outside the body without incubating them inside the abdomen as usual. The fact might be caused by abnormal circumstances of rearing the crabs in the small glass tank for a long term. In the berried crabs from Honshu, the egg-mass is dark purple in earlier stages, but becomes greenish to green later and the zoca hatched out is greenish as a whole.

As seen in the above-given descriptions, there are indeed many specific characters common to both larvae given by AIKawa and the present writer. ArkawA's crabs were collected on the Pacific coast of the southern Kanto District, probably near the town of Misaki in the Miura Peninsula, while the Iwata's specimens came from Hokkaido. For these reasons, it seems likely that the differences between both larvae may depend on the crabs in different habitats and localities. Dr. Tune SakaI, who is the most-learned specialist of crabs in Japan, suggested the present writer that $P$. quadridens from Hokkaido differs slightly in morphology from that from Honshu. Thus, it may be concluded that the existence of differences in characters between the larvae from Honshu and Hokkaido is a positive support of treating the crabs 
from Hokkaido as a variety of Pugettia quadridens originally described by DE HAAN on the material from Japan, probably from the shore of the southern Japan (1833-1849).

\section{Summary}

The present paper deals with the larval development of Puggettia quadridens (Brachyura, Majidae) from Hokkaido, especially the hatching of eggs and the characters of the prezoea and first zoea. The characters of the first zoea differ somewhat between the crabs from Honshu and Hokkaido.

\section{REFERENCES}

Aikawa, H. 1929. On larval forms of some Brachyura. Rec. Oceanogr. Works in Japan, vol. 2, no. $1 ; 17-55$.

1933. On larval forms of some Brachyura. Paper II; A note on indeterminable zoea. ibid., vol. 5 , no. $2 ; 124-254$.

1935. Inachidae Zoeae. Larval characters of the family Inachidae and allied forms (in Japanese). Zool. Mag., 47; 217-227.

1937. Further notes on Brachyuran larvae. Rec. Oceanogr. Works in Japan, vol. 9, no. 1;

$87-162$.

1941. Additional notes on Brachyuran larvae. ibid., vol. 12, no. 2; 117-120.

*HaAn, W. De. 1833-1849. Crustacea, in: de Stebold, Fauna Japonica.

Iwata, F. 1969. On the development of Pugettia quadridens (in Japanese). Zool. Mag., vol. 78; 382.

Sakat, T. 1965. The crabs of Sagami Bay. Maruzen Co., Ltd. Tokyo; 1-206.

TAKEDA, M. and S. MrYAKE, 1968. First zoeae of two piluminid crabs of the family Xanthidae (in Japanese with English summary). Sci. Bull. Fac. Agr., Kyushu Univ., vol. 23, no. 3; 127-133.

* Not directly referred to. 


\section{EXPLANATION OF PLATES I-II}

Plate I. Pugettia quadridens (DE HAAN), eggs in the hatching stage.

Fig. a. 36 to 39 day egg in the hatching stage, photographed on March 7, 1969.

Figs. b and c. 35 to 39 day egg in the hatching stage, photographed on March 1, 1969.

Figs. d and e. 34 to 36 day egg in the hatching stage, photographed on March 8, 1969.

Fig. f. Egg shell cast off with a lot of marine ciliates.

ae. antennule, an. antenna, bo. boundary between the telson and the caudal furca, ch. chromatophore, d. deutoplasm, e. compound eye, fm. first maxilliped, m. mandible, me. maxillule, sm. second maxilliped.

Plate II. Pugettia quadridens (DE HAAN), prezoea and first zoea.

Fig. a. Prezoea after 43 to 46 days, photographed on March 14, 1969.

Fig. b. First zoea after 33 days, photographed on March 10, 1969.

Figs. c and e. First zoea after 43 to 46 days, photographed on March 14, 1969.

Fig. d. First zoea after 31 days, photographed on March 9, 1969.

b. buds of legs, bp. buds of pleopods, ds. dorsal spine, h. heart, 1. labrum, ns. needle-like seta on carapace, $r$. rostral spine, rd. rudiment of dorsal spine, t. third maxilliped. 
Publ. Seto Mar. Biol. Lab., XVIII (3), 1970.

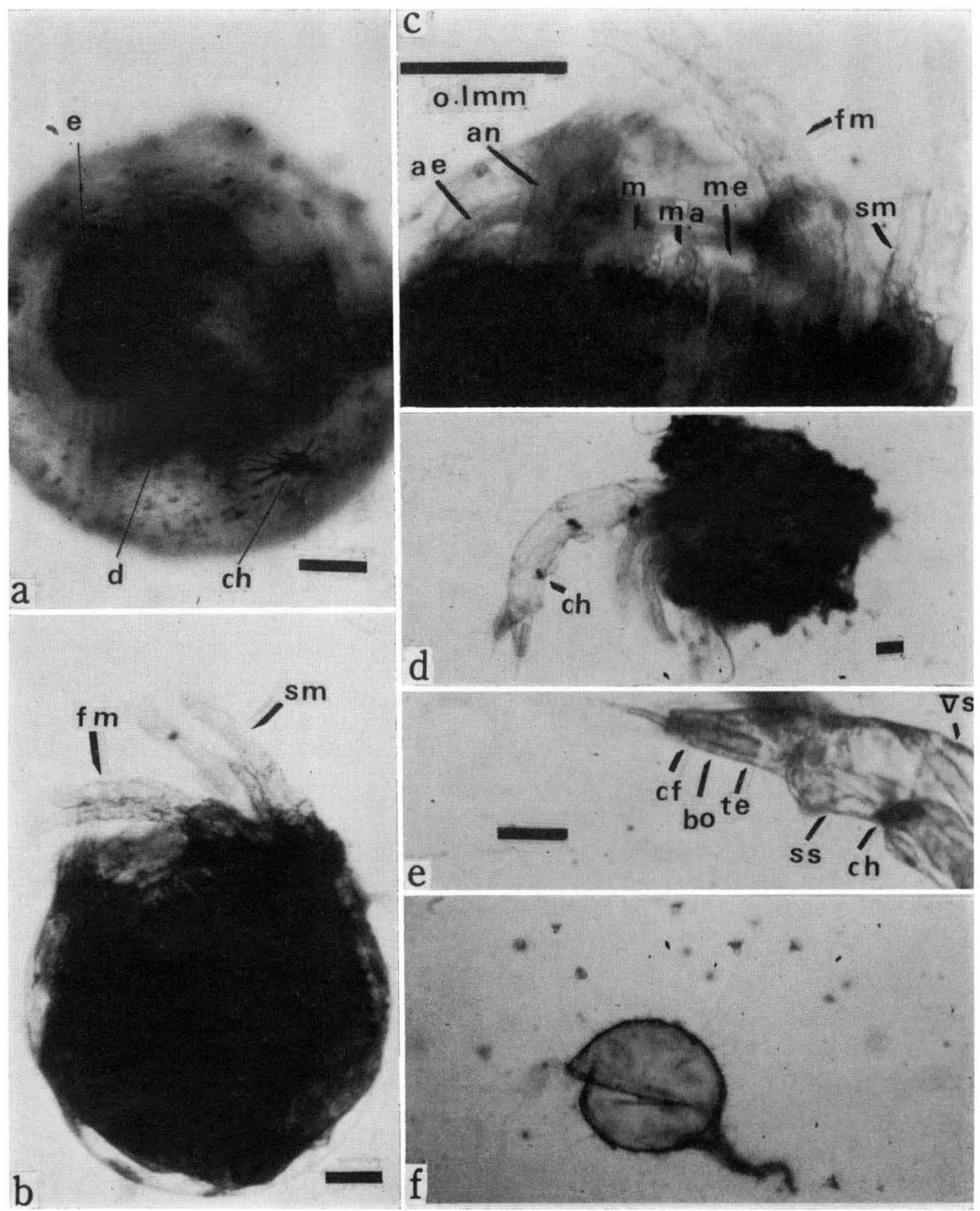

F. Iwata : Development of Pugettia quadridens, 1 
Publ. Seto Mar. Biol. Lab., XVIII (3), 1970.

PLATE II
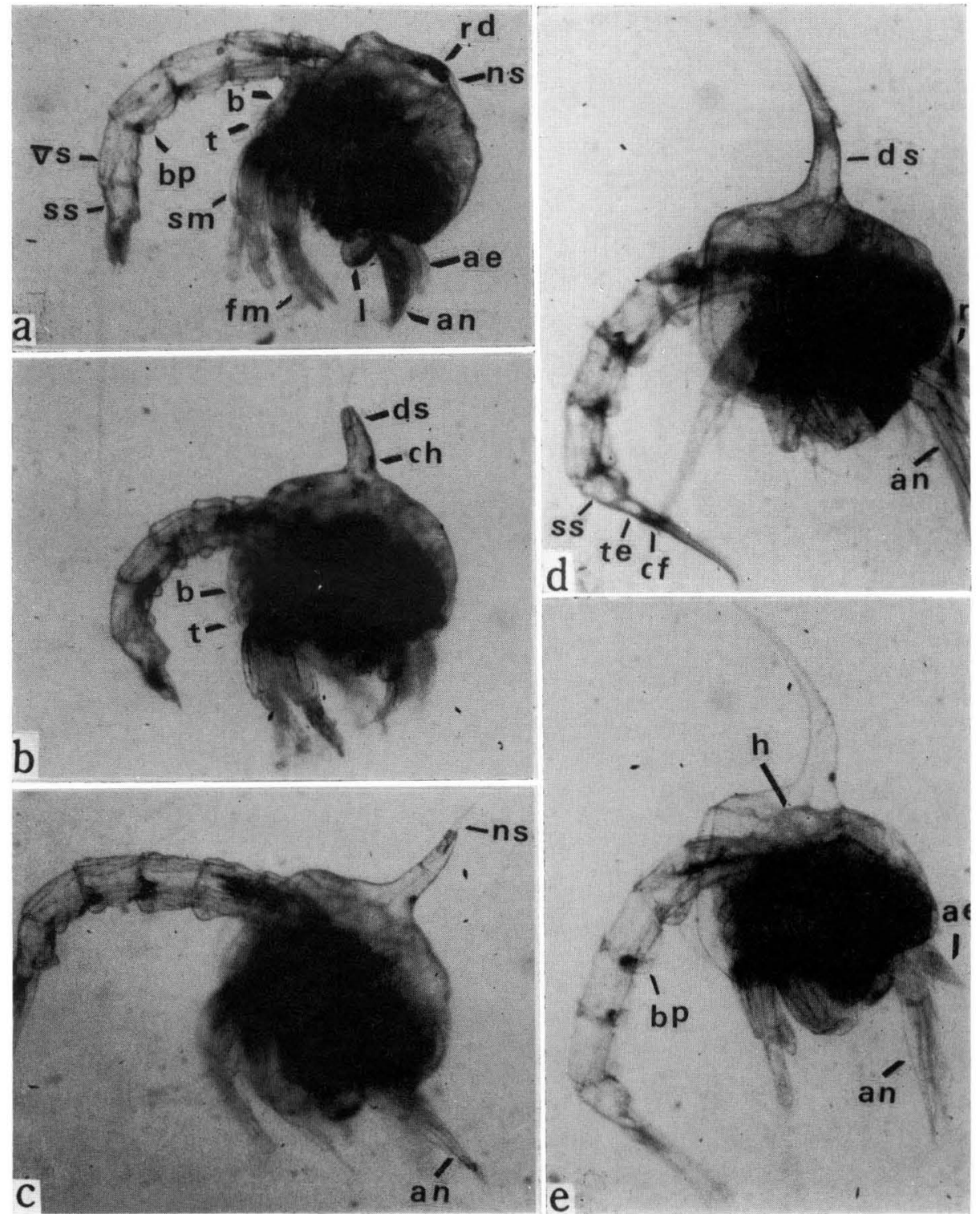

F. Imata: Development of Pugettia quadridens, 1 